\title{
Analysis of Organic Central Nervous System Disorder in Full-Term and Premature Children Depending on the Factors of Risk and Comparison of Their Rehabilitation Efficiency
}

\author{
Olga Kovalenko ${ }^{1}$ and Volodymyr Abramenko ${ }^{2}$ \\ 1. National Medical Academy of Post-Graduate Education Named After P.L., Shupik. Kiev, Street Dorogozhytska 904112, Ukraine \\ 2. Department of Health Care, Ukrainian Medical Rehabilitation Centre for Children with Organic Disorders of Nervous System, \\ Ministry of Health of Ukraine, Kiev, Street Bogatyrskaya 30 04209, Ukraine
}

\begin{abstract}
There are provided the observation results of the clinical anamnesis data of 193 families. Depending on the gestational age of the new born child, they have been divided into 2 groups: the 1st major (full-term) and 2nd control (premature). They have been compared to each other by a history (pre-natal, natal, post-natal) according to the criteria of efficiency and rehabilitation (test form GMFM-88), applying scalp acupuncture, with the physical therapy and therapeutic massage. The received results extend the data concerning risk factors that affect embryogenesis, infant's central nervous system and effectiveness of rehabilitation measures.
\end{abstract}

Key words: Infant cerebral palsy spastic form, a RF (risk factor), CNS (central nervous system), scalp acupuncture, full-term, premature, disability.

\section{Introduction}

The basis for program maintenance and rehabilitation of premature children is the assessment of the physical development - one of the informative indicators of their health [1]. This primarily relates to increasing of knowledge and skills for the diagnosis, prevention, treatment and rehabilitation of children with neurological disorders. The clinical examination, ability of qualified designation and implementation of individual rehabilitation programs for children with organic lesions (disorders) of the nervous system becomes significant importance in this issue (Ministry of Health of Ukraine of 08.10.2007 order № 623 “On approval of individual rehabilitation program for disabled, disabled child and their preparation procedure").

There is a direct correlation between anthropometric

Corresponding author: Volodymyr Abramenko, research field: neurology childhood. E-mail: v_abramenko@yahoo.com. data of the newborn, its subsequent physical, psychomotor and neurological development. Fetus is developing in difficult circumstances and relationships both with the mother and the environment $[2,3]$. Physical development varies considerably in violation of these relationships $[4,5]$. According to the indicators of physical development at birth (abording), as the starting level, are important, as reflecting features of fetal development and they are prognostically significant for future years of life [6-8].

Many authors note that the most important factors that lead to lower body weight at birth are mother's age, anthropometric characteristics of both parents, mother's weight and body length at birth, late registration with the antenatal clinic, residence, pregnancy and delivery flow, the umbilical cord pathology, mother's smoking, cardiovascular disease, fetoplacental insufficiency, oligohydramnios and uterine fibroids and endocrine pathology of mother. 
Consequently, smoking during pregnancy duplicates the likelihood of a negative outcome [9-12].

The vast majority of diseases in the neonatal period and many diseases in older age represent the prolonged pathology of the embryo and fetus. Therefore, to reduce the number of adverse outcomes and improve the remote forecast in prematurely born children, the study of factors affecting their physical development is considered of paramount importance and effectiveness of rehabilitation measures, applying scalp acupuncture, adapted for children from the 3rd-4th of life, with the passive and active physical therapy and therapeutic massage.

\section{Aim}

The analysis of pathogenic factors on qualitative and quantitative characteristics of risk factors affects embryogenesis and infant's CNS (central nervous system). This monitoring influences on effectiveness of rehabilitation by the non-drug measures (scalp acupuncture, physical therapy and therapeutic massage) of these patients groups.

\section{Materials and Methods}

There was observed data of two groups including 193 children: (1) 1st group (main), 83 full term born children, 50 boys $(60.24 \pm 5.37 \%)$ and 33 girls (39.76 \pm $5.37 \%$ ), the average age of the group was $28.8 \pm 18$ months; (2) 2nd group (control), 110 prematurely born children: 66 boys $(60.00 \pm 4.67 \%)$ and 44 girls $(40.00 \pm$ $4.67 \%$ ), the average age of the group was $26.0 \pm 1.5$ months.

The following criteria were observed: (1) the age and presence of bad habits in parents at the time of pregnancy (Fig. 1 and Table 1); (2) features of preliminary and current pregnancy (Table 2); (3) the nature of transaction, complications and moon phase (Fig. 2) at the time of delivery; (4) features of an infant's postnatal period (Table 3 and Fig. 3), when the diagnosis was established for the first time (Fig. 4), analysis of spastic forms according to the International Classification of Diseases (ICD-10) (Fig. 5).

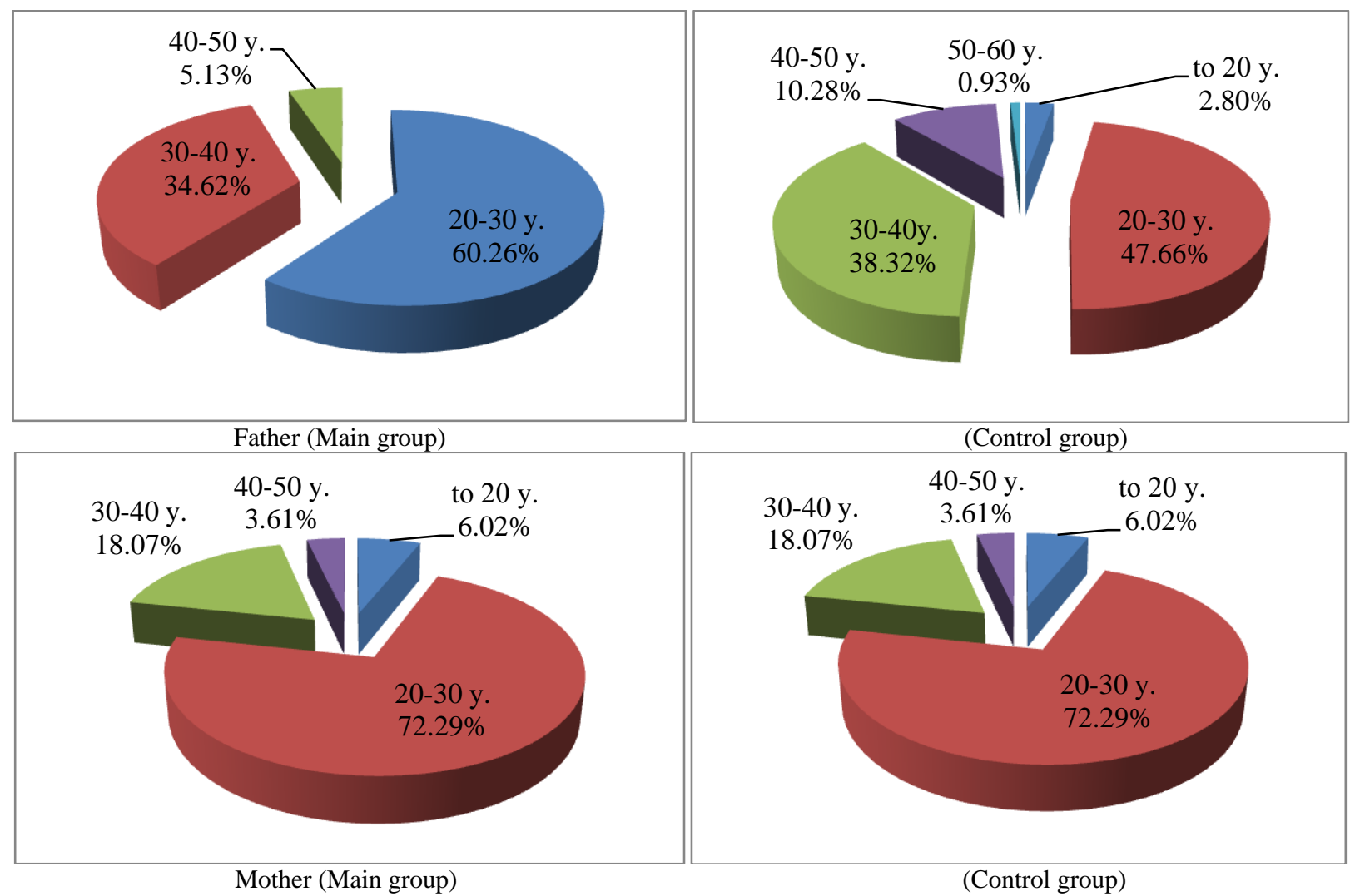

Fig. 1 Age subgroups of parents for the period of childbirth (\%). 

on the Factors of Risk and Comparison of Their Rehabilitation Efficiency

Table 1 Average age of parents and presence of addictions, for the period of this pregnancy (\%).

\begin{tabular}{lll}
\hline \multirow{2}{*}{ Parents } & \multicolumn{2}{c}{ Average age of parents for the period of childbirth } \\
\cline { 2 - 3 } & Main group & Control group \\
\hline Father & $28.9 \pm 0.7 \mathrm{y}$. & $30.06 \pm 0.7 \mathrm{y}$. \\
Mother & $25.6 \pm 0.6 \mathrm{y}$. & $26.7 \pm 0.6 \mathrm{y}$. \\
\hline Alcohol abuse & & $14.0 \pm 3.4 \%$ \\
\hline Father & $9.0 \pm 3.2 \%$ & $0.9 \pm 0.9 \%$ \\
Mother & $2.4 \pm 1.7 \%$ & \\
\hline Smoking & & $56.1 \pm 4.8 \%$ \\
Father & $48.7 \pm 5.7 \%$ & $10.9 \pm 3.0 \%$ \\
\hline
\end{tabular}

Table 2 Features of previous and this pregnancy $(\%)$.

\begin{tabular}{|c|c|c|}
\hline & Main group & Control group \\
\hline Brothers/sisters & $21.69 \pm 4.52 \%$ & $45.45 \pm 4.75 \%$ \\
\hline Miscarriages & $14.46 \pm 3.24 \%$ & $16.36 \pm 3.53 \%$ \\
\hline Abortions & $7.23 \pm 2.84 \%$ & $19.1 \pm 3.7 \%$ \\
\hline Stillbirth & $2.41 \pm 1.68 \%$ & $1.8 \pm 1.3 \%$ \\
\hline Mortality of children at an early age & $3.6 \pm 2.0 \%$ & $1.8 \pm 1.3 \%$ \\
\hline \multicolumn{3}{|l|}{ Childbirth in succession: } \\
\hline - the $1 \mathrm{st}$ & $78.0 \pm 4.6 \%$ & $69.4 \pm 4.4 \%$ \\
\hline - the 2 nd & $19.5 \pm 4.4 \%$ & $26.9 \pm 4.3 \%$ \\
\hline - the $3 \mathrm{rd}$ & $2.4 \pm 1.7 \%$ & $3.7 \pm 1.8 \%$ \\
\hline Diseases of mother for the period of pregnancy & $39.8 \pm 5.4 \%$ & $34.5 \pm 4.5 \%$ \\
\hline \multicolumn{3}{|l|}{ Toxicosis: } \\
\hline - 1st half & $42.2 \pm 5.4 \%$ & $40.0 \pm 4.7 \%$ \\
\hline - 2nd half & $16.9 \pm 4.1 \%$ & $22.7 \pm 4.0 \%$ \\
\hline - 1st and 2 nd half & $41.0 \pm 5.4 \%$ & $37.3 \pm 4.6 \%$ \\
\hline $\mathrm{Rh}$ (Rhesus factor) incompatibility & $3.6 \pm 2.0 \%$ & $7.3 \pm 2.5 \%$ \\
\hline \multicolumn{3}{|l|}{ Interruption threat: } \\
\hline - 1st half & $20.5 \pm 4.4 \%$ & $19.1 \pm 3.7 \%$ \\
\hline - 2nd half & $9.6 \pm 3.2 \%$ & $18.2 \pm 3.7 \%$ \\
\hline - 1st and 2nd half & $12.0 \pm 3.6 \%$ & $15.5 \pm 3.4 \%$ \\
\hline Infectious diseases of mother for the period of pregnancy & $12.0 \pm 3.6 \%$ & $13.6 \pm 3.3 \%$ \\
\hline \multicolumn{3}{|l|}{ Anemia of pregnant women: } \\
\hline-1 st half & $7.2 \pm 2.8 \%$ & $11.8 \pm 3.1 \%$ \\
\hline - 2nd half & $1.2 \pm 1.2 \%$ & $6.4 \pm 2.3 \%$ \\
\hline - 1st and 2nd half & $16.9 \pm 4.1 \%$ & $16.4 \pm 3.5 \%$ \\
\hline Arterial hypertension & $10.8 \pm 3.4 \%$ & $18.2 \pm 3.7 \%$ \\
\hline Arterial hypotension & $16.9 \pm 4.1 \%$ & $15.5 \pm 3.4 \%$ \\
\hline \multicolumn{3}{|l|}{ Nephropathy: } \\
\hline - 2nd half & $13.3 \pm 3.7 \%$ & $0.9 \pm 0.0 \%$ \\
\hline - 1st and 2 nd half & $1.2 \pm 1.2 \%$ & $2.7 \pm 1.6 \%$ \\
\hline
\end{tabular}

For the further analysis, to compare the effectiveness of rehabilitation measures between children born in full term and preterm (Tables 4 and 5), these groups were additionally divided into:

(1a) main group $n=41$, full-term ( $37 \pm 2.6$ months); (1b) control group, $n=55$, preterm ( $36 \pm 3.6$ months), with whom a comprehensive, simultaneous combination of passive and active physical therapy (physiotherapy), taking into consideration neurology of development, therapeutic massage scalp acupuncture were applied as pathogenetically grounded neyrorehabilitational methods; (2a) main group, $n=30$, full-term (34.2 \pm 3.1 months); (2b) control group, $n=$ 45 , preterm ( $35.7 \pm 2.6$ months), where "traditional" treatment without the use of scalp acupuncture was applied. 


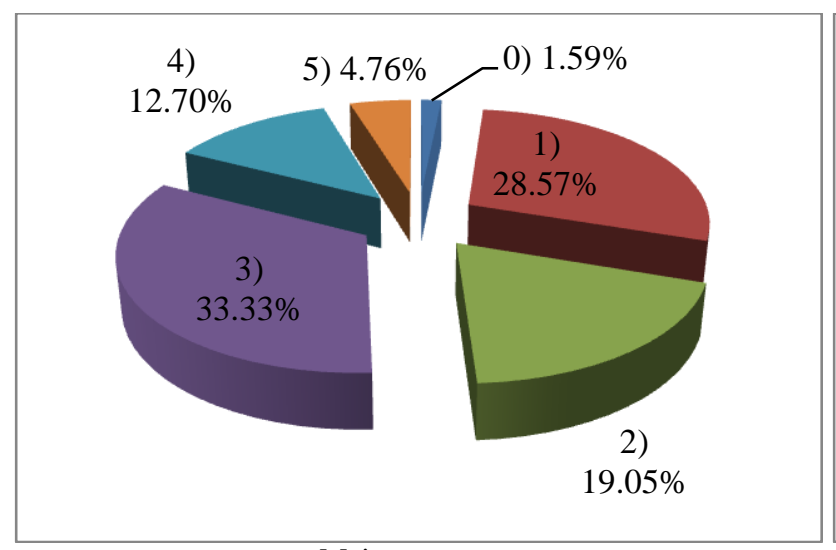

Main group

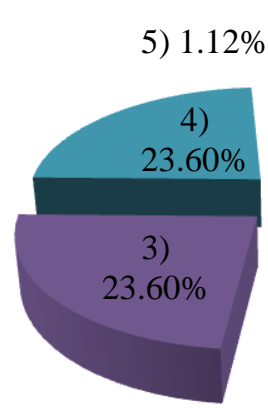

0) $1.12 \%$

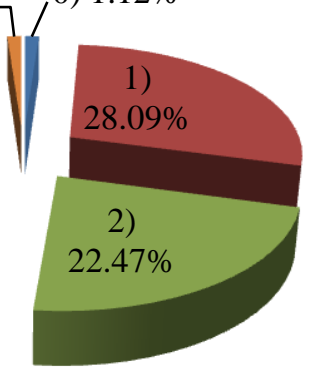

Fig. 2 The moon phases for the period of childbirth (\%).

Table 3 Childbirth, features of the post-natal period (\%).

\begin{tabular}{|c|c|c|}
\hline & Main group & Control group \\
\hline Cesarean section (according to the emergency indications) & $13.3 \pm 3.7 \%$ & $28.2 \pm 4.3 \%$ \\
\hline \multicolumn{3}{|l|}{ Fetal water: } \\
\hline - dirty & $21.9 \pm 4.8 \%$ & $11.5 \pm 3.6 \%$ \\
\hline - polyhydramnios & $4.1 \pm 2.3 \%$ & $6.4 \pm 2.8 \%$ \\
\hline - oligohydramnios & $4.1 \pm 2.3 \%$ & $2.6 \pm 1.8 \%$ \\
\hline Metrypercinesia (Fast childbirth) & $12.0 \pm 3.6 \%$ & $31.8 \pm 4.4 \%$ \\
\hline Prolonged labor (Long childbirth) & $42.2 \pm 5.4 \%$ & $9.1 \pm 2.7 \%$ \\
\hline Weakness of patrimonial activity & $31.3 \pm 5.1 \%$ & $16.4 \pm 3.5 \%$ \\
\hline Application of forceps & $3.03 \pm 2.11 \%$ & 0 \\
\hline Vacuum & 0 & $43.08 \pm 6.14 \%$ \\
\hline Medical stimulation & $63.6 \pm 5.9 \%$ & $43.1 \pm 6.1 \%$ \\
\hline Physical stimulation & $33.3 \pm 5.8 \%$ & $9.2 \pm 3.6 \%$ \\
\hline \multicolumn{3}{|l|}{ Complicated childbirth: } \\
\hline (a) defects of umbilical cord & $12.0 \pm 3.6 \%$ & $6.4 \pm 2.3 \%$ \\
\hline (b) anomalies praevia (of presentation) & $6.0 \pm 2.6 \%$ & $9.1 \pm 2.7 \%$ \\
\hline (c) premature detuning of placenta & $3.6 \pm 2.0 \%$ & $10.9 \pm 3.0 \%$ \\
\hline (d) disproportion of pelvic size/fetus & $2.4 \pm 1.7 \%$ & 0 \\
\hline (e) premature/lateness (delay) & $6.0 \pm 2.6 \%$ & $20.0 \pm 3.8 \%$ \\
\hline \multicolumn{3}{|l|}{ bursting of waters } \\
\hline (i) anhydrous period of more than 6 hours & $31.3 \pm 5.1 \%$ & $12.7 \pm 3.2 \%$ \\
\hline Gestational age & $39.6 \pm 0.2 \mathrm{wk}$ & $31.3 \pm 0.3 \mathrm{wk}$ \\
\hline Body weight & $3337.1 \pm 52.7 \mathrm{gm}$ & $1786.6 \pm 52.5 \mathrm{gm}$ \\
\hline Length of body & $51.7 \pm 0.3$ & $42.2 \pm 0.6$ \\
\hline Circle of the head & $35.2 \pm 0.4$ & $29.8 \pm 0.5$ \\
\hline \multicolumn{3}{|l|}{ Apgar Scale: } \\
\hline$-1-3$ & $21.54 \pm 5.10 \%$ & $15.5 \pm 3.9 \%$ \\
\hline$-4-6$ & $30.77 \pm 5.72 \%$ & $54.8 \pm 5.4 \%$ \\
\hline$-7-10$ & $47.69 \pm 6.20 \%$ & $29.8 \pm 5.0 \%$ \\
\hline \multicolumn{3}{|l|}{ Birth trauma: } \\
\hline - absence & $62.16 \pm 5.64 \%$ & $86.9 \pm 3.7 \%$ \\
\hline - traumatic injuries (damages) of soft tissues of the head, of the skull bones & $27.03 \pm 5.16 \%$ & $4.8 \pm 2.3 \%$ \\
\hline - intracranial hemorrhages & $9.46 \pm 3.40 \%$ & $4.8 \pm 2.3 \%$ \\
\hline \multicolumn{3}{|l|}{ CNS: } \\
\hline - hypoxemic ischemic encephalopathy & $49.4 \pm 5.49 \%$ & $30.9 \pm 4.4 \%$ \\
\hline - subependymal hemorrhage + intra ventricular hemorrhage & $6.02 \pm 2.61 \%$ & $17.3 \pm 3.6 \%$ \\
\hline Bilirubin binding encephalopathy & $6.0 \pm 2.6 \%$ & $18.2 \pm 3.7 \%$ \\
\hline Congenital (Inborn) malformations & $8.4 \pm 3.1 \%$ & $9.1 \pm 2.7 \%$ \\
\hline \multicolumn{3}{|l|}{ From the hospital was transferred to: } \\
\hline - department of pathology of newborns & $54.3 \pm 5.5 \%$ & $85.8 \pm 3.4 \%$ \\
\hline - at home & $42.0 \pm 5.5 \%$ & $9.4 \pm 2.8 \%$ \\
\hline
\end{tabular}


Analysis of Organic Central Nervous System Disorder in Full-Term and Premature Children Depending 131 on the Factors of Risk and Comparison of Their Rehabilitation Efficiency

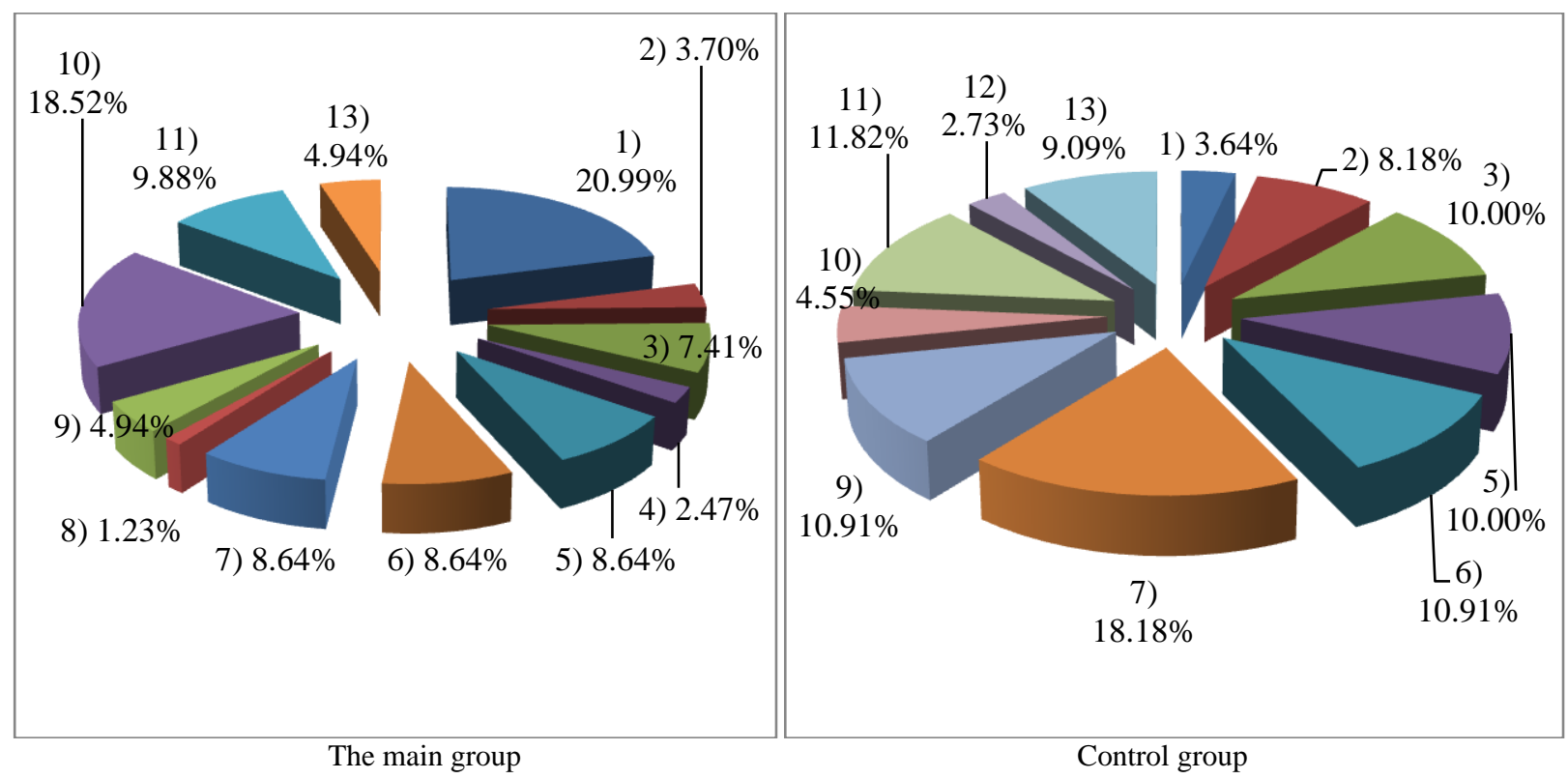

Fig. 3 Syndromes of the newborn period (\%).

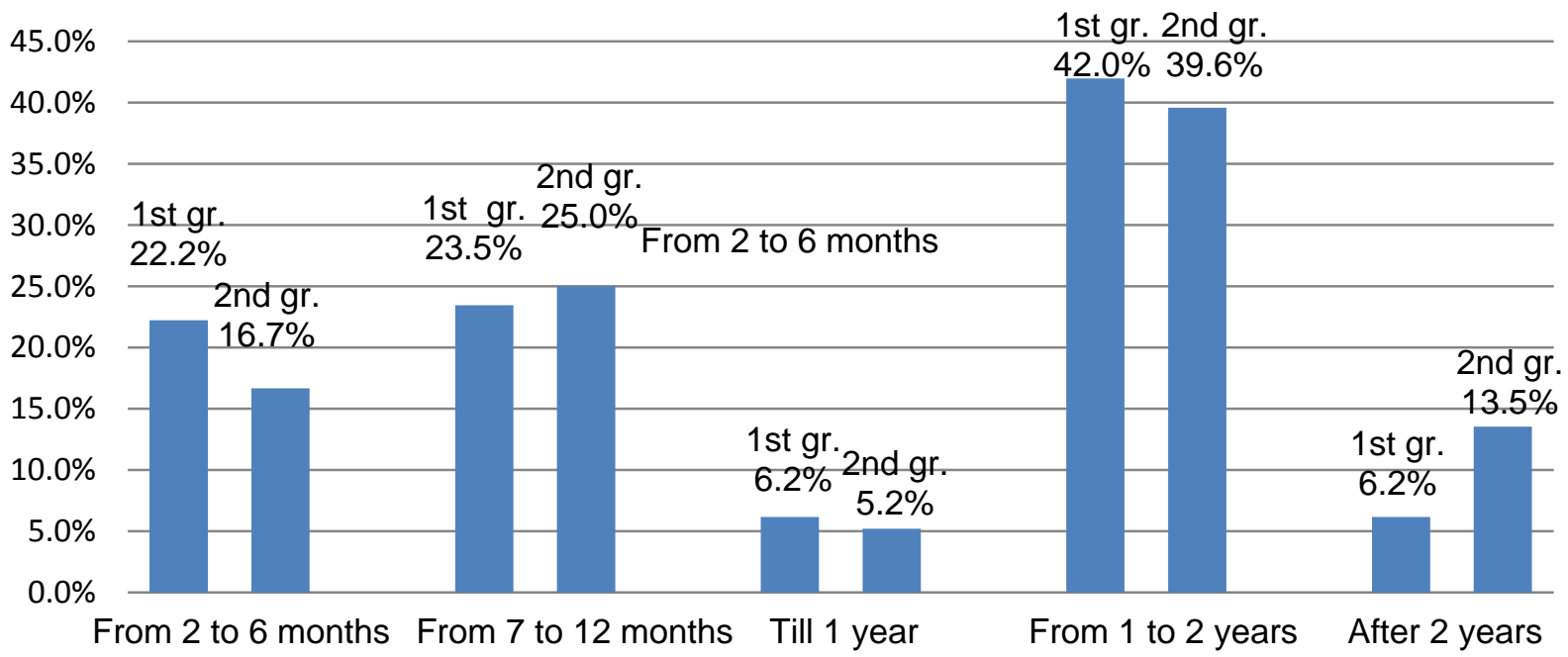

Fig. 4 The child's age, when the diagnosis is established for the first time (\%).

The effectiveness of simultaneous physiotherapy integrated with scalp acupuncture in patients with cerebral palsy was conducted on a scale of gross motor function (GMFM (ross motor function measure)-test form 88) [13-15], which is the standardized and proven tool to determine changes in gross motor function in children with cerebral palsy.

To accomplish this goal clinical and medical history, neuroimaging and analytical-statistical methods were used.

\section{Results}

The following data have been obtained at the assessment of above-mentioned criteria. This data is reflecting quantity and percent of the factors related to the anamnesis of parents and sick children's lives.

As a result of the graphic representation analysis (Fig. 1) of age subgroups and average parents' age (Table 1), statistical difference between the main and control groups has not been revealed. 


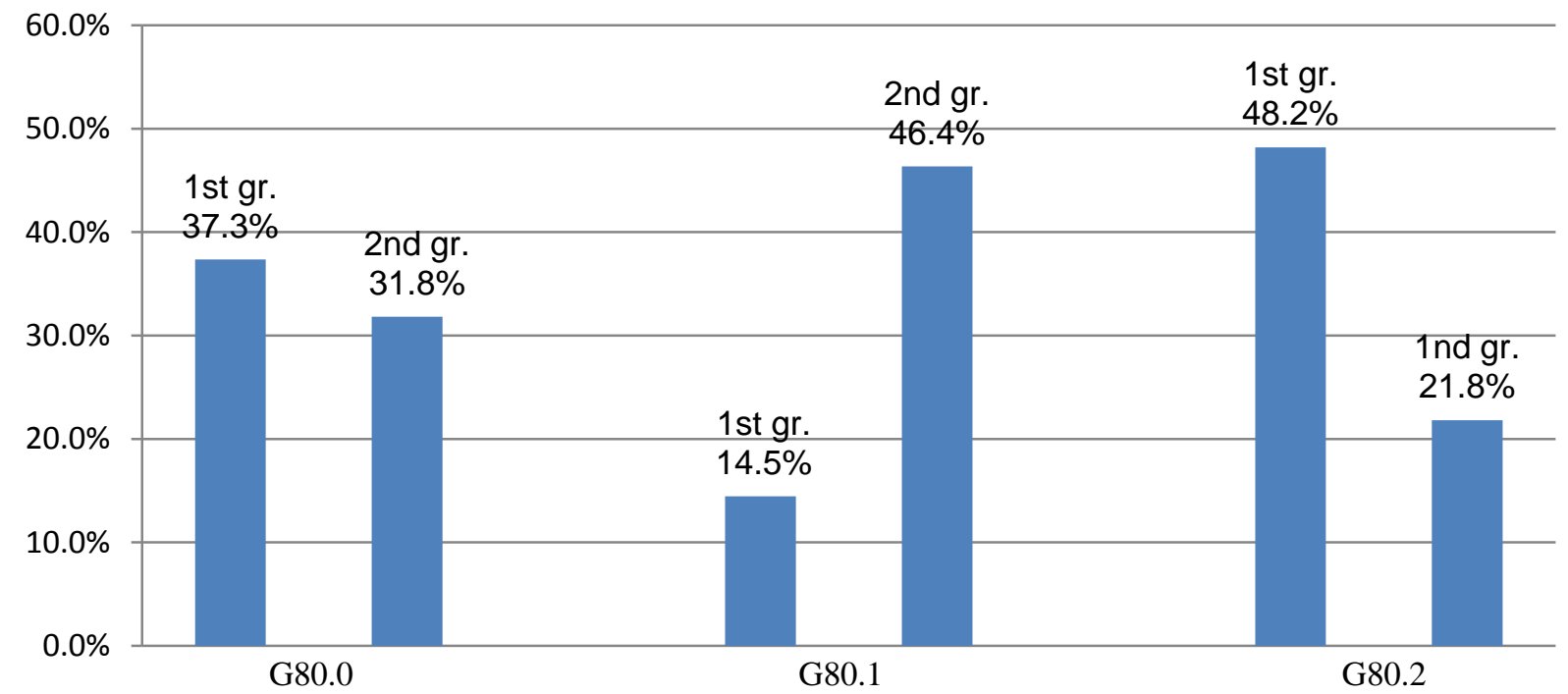

Fig. 5 The diagnosis of children on International Classification of Diseases (\%).

Table 4 Comparison of efficiency on the test GMFM-88 form (\%).

\begin{tabular}{lllllll}
\hline Difference between & $\mathrm{A}$ & $\mathrm{B}$ & $\mathrm{C}$ & $\mathrm{D}$ & $\mathrm{E}$ & general \\
\hline \multicolumn{6}{l}{ Complex, simultaneous combination of passive and active physiotherapy exercises, medical massage about scalp acupuncture } \\
\hline 1-a group full-term & $4.7 \pm 1.2 \%$ & $3.54 \pm 1.12 \%$ & $3.9 \pm 1.2 \%$ & $3.5 \pm 1.0 \%$ & $1.9 \pm 0.7 \%$ & $3.5 \pm 0.7 \%$ \\
1-b group premature & $7.91 \pm 1.14 \%$ & $3.39 \pm 0.72 \%$ & $3.07 \pm 0.8 \%$ & $2.56 \pm 0.68 \%$ & $1.9 \pm 0.7 \%$ & $3.8 \pm 0.6 \%$ \\
\hline "Traditional" treatment without use of scalp acupuncture & & & & \\
\hline 2-a group full-term & 0 & 0 & 0 & 0 & 0 & 0 \\
2-b group premature & $0.52 \pm 0.22 \%$ & $0.15 \pm 0.15 \%$ & 0 & 0 & 0 & 0 \\
\hline
\end{tabular}

Table 5 The statistical difference between 1-a main and 1-b control groups (pt/\%).

\begin{tabular}{|c|c|c|c|c|c|}
\hline & \multicolumn{2}{|c|}{ 1-a main group full-term } & \multicolumn{2}{|c|}{ 1-b control group premature } & \multirow[b]{2}{*}{$P$} \\
\hline & $\mathrm{pt} / \%$ & $\pm \mathrm{n}$ & $\mathrm{pt} / \%$ & $\pm \mathrm{n}$ & \\
\hline $\mathrm{A}$ & 2.4 & 0.6 & 7.9 & 1.1 & $<0.05$ \\
\hline $\mathrm{A} \%$ & 4.7 & 1.2 & 7.91 & 1.14 & $>0.05$ \\
\hline $\mathrm{B}$ & 2.18 & 0.69 & 2.04 & 0.43 & $>0.05$ \\
\hline $\mathrm{B} \%$ & 3.54 & 1.12 & 3.39 & 0.72 & $>0.05$ \\
\hline $\mathrm{C}$ & 1.7 & 0.5 & 1.29 & 0.34 & $>0.05$ \\
\hline $\mathrm{C} \%$ & 3.9 & 1.2 & 3.07 & 0.80 & $>0.05$ \\
\hline $\mathrm{D}$ & 1.4 & 0.4 & 1.00 & 0.26 & $>0.05$ \\
\hline $\mathrm{D} \%$ & 3.5 & 1.0 & 2.56 & 0.68 & $>0.05$ \\
\hline $\mathrm{E}$ & 1.4 & 0.5 & 1.4 & 0.5 & $>0.05$ \\
\hline $\mathrm{E} \%$ & 1.90 & 0.70 & 1.9 & 0.7 & $>0.05$ \\
\hline general assessment & 3.5 & 0.7 & 3.8 & 0.6 & $>0.05$ \\
\hline
\end{tabular}

Differences between the main and control groups have not been revealed at the research of addictions (smoking, alcohol abuse).

It is revealed at the research, that the control group has more burdened obstetric anamnesis, on indicators: brothers/sister $(45.45 \pm 4.75 \%)$, abortions (19.1 \pm $3.7 \%$ ), anemia of the 2 nd half of pregnancy (64 \pm
$2.3 \%$ ), but the basic group by the quantity of nephropathy of the 2 nd half of pregnancy $(13.3 \pm 3.7 \%)$ prevails the control.

Credibly statistical difference between the main and control groups while analyzing graphic representation of the moon phases is not found.

The result of childbirth features research, their 
maintaining and complications, looked as follows. Main group on indicators: prolonged labor $-42.2 \pm$ $5.4 \%$; weakness of patrimonial activity (slow labor) $-31.3 \pm 5.1 \%$; medical stimulation- $63.6 \pm$ $5.9 \%$; physical stimulation-33.3 $\pm 5.8 \%$; latency period more than 6 hours $-31.3 \pm 5.1 \%$, prevails the control group. It is necessary to pay attention in control group to premature placental abruption-10.9 $\pm 3.0 \%$, bursting of waters $-20.0 \pm 3.8 \%$ that explains number of Cesarean sections $-28.2 \pm 4.3 \%$ and precipitancy of childbirth (sorts) $-31.8 \pm 4.4 \%$, almost in $1 / 2$ cases vacuum extraction was carried out.

The control group considerably falls behind on gestational age and anthropometrical data $(11 \mathrm{~cm}-14$ $\mathrm{cm}$, see in Table 3), that explains its bigger percent from the 4 to 6 on Apgar scale-54.8 $\pm 5.4 \%$, of subependimal hemorrhages + intra ventricular hemorrhage-17.3 $\pm 3.6 \%$, bilirubin binding encephalopathies-18.2 $\pm 3.7 \%$ and quantity of children transferred from maternity hospital-85.8 \pm $3.4 \%$ into the department of pathology of newborns, in comparison with main group. But despite considerable percent from 7 to 10 points $-47.69 \pm 6.20 \%$ on Apgar scale, the main group considerably exceeds on traumatic damages of soft tissues of the head, bones of skull $27.03 \pm 5.16 \%$ and hypoxemic ischemic encephalopathy $49.40 \pm 5.49 \%$.

Where: 1) it is discharged neurologically recovered; 2) hypertensive-hydrocephal; 3) hydrocephal; 4) mikrocephal; 5) muscular hypotonia; 6) muscular dystonia/dyskinesia; 7) motive disturbances (paresis, paralyzes); 8) bulbar, pseudobulbar; 9) hyper excitabilities; 10) convulsive, epileptic; 11) muscular hypertonia; 12) delay of statokinetic development; 13) others.

The convulsively epileptic syndrome prevails other pathological neurologic syndromes on specific difference in main group $-18.57 \pm 4.3 \%$, and motive disturbances prevail in control $18.18 \pm 3.7 \%$, which is illustrated in graphic representation.

In the analysis of graphic representation (Fig. 4), difference between full-term and premature is not observed, as it has been established at the age of diagnosis statement.

On graphic representation, it is observed that in comparison between the main and control groups, on International Classification of Diseases (ICD 10), the hemiparetic form G 80.2-48.2 $\pm 5.48 \%$ prevails at the full-term children, and diplegia form of cerebral spastic infantile paralysis G $80.1-46.4 \pm 4.75 \%$ prevails at the premature.

Efficiency was estimated, as difference between: A \% (lying and turns (17 skills) - the general point $\left(\_51 \times\right.$ $100=\ldots \%)) ; \mathrm{B} \%$ (seats $(20$ skills $)-\left(\_/ 60 * 100=\right.$ — \%)); $\mathrm{C} \%$ (crawling and moving on the knees (14 skills) - $\left.\left(\_/ 42 * 100=\ldots \%\right)\right) ; \mathrm{D} \%$ (standing (13 skills) - $\left.\left(\_/ 39 * 100=\ldots \%\right)\right) ; \mathrm{E} \%$ (walking, running, jumping (the 24th skills) $-(\ldots / 72 * 100=\ldots \%))$, and with the general estimates $(\mathrm{A} \%+\mathrm{B} \%+\mathrm{C} \%+\mathrm{D} \%+$ $\left.\mathrm{E} \% / 5==_{-} \%\right)$ at the beginning and after the treatment. Where as criterion, the following assessment points were considered (examined): 0 - does not try to carry out; 1-starts carrying out; 2-partially carries out; 3 - completely carries out; NT — was not tested.

We have not received visible results where "traditional" treatment, without the use of scalp acupuncture, was applied, therefore the difference between 2-a main and 2-b control groups was not considered further.

When using scalp acupuncture in 1-a main and 1-b control groups, we have received statistical result, but the differences in efficiency of rehabilitation of physical activity between children who were born the full-term and premature is not established (see Table 5).

\section{Conclusions}

Statistically reliable difference on age of parents and addictions has not been found.

As a result of research, it is revealed that the control group had more burdened obstetric anamnesis and the 
pathological course of pregnancy than the main one $(\leq$ $0.05)$.

At research of childbirth (sorts) features, their maintaining and complications, it has been established that main group authentically differs on prolonged labor, weakness of patrimonial activity, medical and physical stimulation and the anhydrous period for more than 6 hours that can promote dominance of quantity hypoxemic-ischemic encephalopathies, traumatic damages of soft tissues of the head and bones of skull.

Fetoplacental insufficiency and premature birth are major factors of the birth of premature children, where mostly: premature placental abruption and bursting of waters, explains number of Cesarean sections and precipitancy of childbirth.

Deviation among the factors promoting pathological currents, conducting of childbirth, complications and after-effects show non randomness in considerable deterioration of specific gravity of the newborn period syndromes in both groups and the control group prevails on somatic insufficiency among the newborns transferred to department of pathology.

Statistically reliable difference is not revealed when comparing efficiency of applying scalp acupuncture between children who were born 1-a (full-term) and $1-b$ (premature), concerning statistical difference in recovery of physical activity, on scale of motor functions (the test GMFM-88 form).

\section{References}

[1] Veltishchev, Yu. E., and Vetrov, V. P. 2000. Objective Indicators of Normal Development and State of Health of the Child. Moscow: Medicine. (in Russian)

[2] Fildinq, J. E. 2006. "Smoking and Women: Tragedy of the Majority." New Engl. J. Med. 317 (21): 1343-5.

[3] Fingerhut, L. A., Kleinman, J. C., and Kendrick, J. S. 2003. "Smoking before, during, and after Pregnancy." Am. J. Pablic Health 80: 541-4.

[4] Prakhin, E. I., and Gritsinsky, V. L. 2004. "Characteristic of Methods of an Assessment of Physical Development of Children." Pediatrics 2: 60-2. (in Russian)
[5] Shabalov, N. P., and Tsvelev, Yu. V. 2002. Perinatologiya Bases. Moscow: Medical Press Inform: 576. (in Russian)

[6] Demyanov, T. G., Grigoryants, L. Ya., Avdeev, T. G., and Rumyantsev, A. G. 2006. Supervision over Deeply Premature Children on the First Year of Life. Moscow: Medical Practice, 148. (in Russian)

[7] Alyamovsky, G. A., and Keshishan, E. S. 2009. "Features of Physical Development on the First Year of Life of Children with Weight at the Birth Less than 1500 Group." Russian Messenger of a Perinatologiya and Pediatrics 3: 20-8. (in Russian)

[8] Yatsyk, G. V., Borovik, T. E., and Gribakin, S. G. 2009. "Metabolic Adaptation of a Fetus and the Newborn to Conditions of Extra Eterine Life." Russian Pediatric Magazine 4: 39-42. (in Russian)

[9] Meis, P. J., Michelutte, R. L., Peters, T. J., Wells, H. B., Sands, R. E., Coles, E. C., and Johns, K. A. 1995. "Factors Associated with Preterm Birth in Cardiff, Wales. I. Univariable and Multivariable Analysis.” Am. J. Obstet. Gynecol. 173 (2): 590-6.

[10] Popovsky, A. I., Kireev, R. A., Ershova, M. V., and Bochkova, L. G. 2008. "Tobacco Syndrome of the Newborn." Saratov's Scientific and Medical Magazine 4: 64-7. (in Russian)

[11] Ilatovsky, D.V. 2011. "Children with a Delay of Prenatal Development: Hormonal Adaptation and Kliniko-psychological Features." Ph.D. thesis, The Voronezh University. (in Russian)

[12] Ovodkova, O. N. 2013. "Physical Development of Newborn Children, for the Last 25 Years in the Voronezh Region.” Ph.D. thesis, The Voronezh University. (in Russian)

[13] Boyce, W., Gowland, C., Rosenbaum, P., Lane, M., Plews, N., Goldsmith, C., Russell, D., Wright, V., Zdrobov, S., and Harding, D. 1992. "Gross Motor Performance Measure for Children with Cerebral Palsy: Study Design and Preliminary Findings." Can. J. Public. Health. 83 (Suppl 2): 34-40.

[14] Palisano, R., Rosenbaum, P., Walter S., Russell, D., and Galuppi, B. 1997. "Development and Reliability of a System to Classify Gross Motor Function in Children with Cerebral Palsy." Dev. Med. Child. Neurol. 39 (4): 214-23.

[15] Eliasson, A. C., Krumlinde Sundholm, L., Rösblad, B., Beckung, E., Arner, M., Öhrvall, A. M., and Rosenbaum, P. 2006. "The Manual Ability Classification System (MACS) for Children with Cerebral Palsy: Scale Development and Evidence of Validity and Reliability." Developmental Medicine and Child Neurology 48: 549-54.( in Ukrainian) 